\title{
Comparison of Dexmedetomidine with Pentazocine and Promethazine in Tympanoplasty Surgeries under Monitored Anaesthesia Care: A Prospective, Randomized, Double Blind Study
}

\author{
Kajal A. Bhatt ${ }^{1}$, Ila A. Prajapati ${ }^{1}$ \\ ${ }^{1}$ Assistant Professor, Dept. of Anaesthesiology, GMERS Medical College \& Civil Hospital, Sola , Ahmedabad, Gujarat, India.
}

\section{Abstract}

Background: Monitored Anaesthesia Care is a planned and suitable technique for tympanoplasty surgeries.The present study has been conducted to compare the effectiveness of dexmedetomidine with combination of pentazocine and promethazine under local anaesthesia with primary end point being the haemodynamic stablity, sedation score and patient and surgeon satisfaction. Subjects and Methods: A prospective randomized double blind study was conducted in 60 ASA grade I-II patients in age groups of 18-60 years undergoing tympanoplasty surgeries. Patients were divided in 2 groups of 30 patients each. Group D received dexmedetomidine loading $1 \mu \mathrm{g} / \mathrm{kg}$ intravenously followed by $0.2 \mu \mathrm{g} / \mathrm{kg} / \mathrm{hr}$ infusion whereas Group PP received pentazocine and promethazine $0.5 \mathrm{mg} / \mathrm{kg}$ intavenously followed by normal saline infusion at $0.2 \mu \mathrm{g} / \mathrm{kg} / \mathrm{hr}$.Patients were assessed for Ramsay sedation score,intraoperative haemodynamic parameters, surgical bleeding score,patient and surgeon satisfaction scores, VAS score, need for rescue analgesics and side effects if any. Results: There was no difference in demographic data in both groups. Ramsay sedation score, surgeon and patient satisfaction scores were significantly higher in Group D than Group PP ( $\mathrm{p}<0.001)$. Intraoperative bleeding scale and Haemodynamic parameters like heart rate,systolic ,diastolic and mean arterial pressure were significantly lower in Group D than Group PP $(p<0.001)$.Lesser number of patients requiring rescue sedatives and analgesics in Group D as compared to Group PP $(\mathrm{p}<0.001)$. There was no significant difference in side effects in both groups. Conclusion: We concluded that Dexmedetomidine provides adequate sedation with better haemodynamic stability,good surgical field vision, surgeon and patient comfort without any adverse effects in tympanoplasty patients under local anaesthesia.

Keywords: Monitored Anaesthesia Care, Dexmedetomidine, Pentazocine, Promethazine, Tympanoplasty, Local Anaesthesia.

Corresponding Author: Dr. Ila A. Prajapati, F /403, Ozone Aangan Residency, Opp. Ramapir Tekra, BRTS Bus Stop, New Vadaj, Ahmedabad-380013 Gujarat, India.

Received: March 2019

Accepted: March 2019

\section{Introduction}

Tympanoplasty involves reconstruction of perforated tympanic membrane with or without ossiculoplasty. ${ }^{[1]}$ It is usually done under local anaesthesia with sedation under monitored anaesthesia care (MAC) or general anaesthesia. ${ }^{[2]}$ According to the American Society of Anaesthesiologists (ASA), a monitored anaesthesia care is a planned procedure during which the patient undergoes local anaesthesia together with sedation and analgesia. Actually MAC is the first choice in $10-30 \%$ of all the surgical procedures. The three fundamental elements and purpose of a conscious sedation during a MAC are: a safe sedation, the control of the patient anxiety and the pain control. The patients undergoing conscious sedation are able to answer to orders appropriately and to protect airways.

Commonly used medications for MAC are benzodiazepines, cPentazocine, Promethazine, propofol. Midazolam with quick onset, but its relatively long half-life can cause prolonged sedation after repeated administration. ${ }^{[3]}$ Combining midazolam with Pentazocine increases the risk for drowsiness and respiratory depression. ${ }^{[4]}$ The addition of Promethazine has been reported to cause oversedation with respiratory depression. ${ }^{[5]}$

Dexmedetomidine, a comparatively newer drug which centrally acts as $\alpha_{2}$ receptor agonist with analgesic and conscious sedative effect without major respiratory depression, has been reported significantly effective both during and after surgery. ${ }^{[6-10]}$ In addition, it has a sympatholytic effect that can attenuate the stress response to surgery and maintains desired controlled hypotension. ${ }^{[11-14]}$

The present study compares dexmedetomidine with a combination of pentazocine-promethazine in patients undergoing tympanoplasty under local anaesthesia with primary end point being the patient and surgeon satisfaction, sedation score and hemodynamic stability. The need of intraoperative rescue analgesics to maintain a cooperative state of the patient was the secondary end point.

\section{Subjects and Methods}

After obtaining approval from the Institutional Ethical Committee and written informed consent,sixty patients of 
American Society of Anaesthesiologists (ASA) physical status I to II of both gender, aged 18-60 years, scheduled for tympanoplasty surgeries under local anaesthesia were enrolled for this prospective, randomised, double blind study over a period of one year. Patients having any cardiac disease,2nd and 3rd degree heart block, chronic obstructive lung disease, renal and hepatic insufficiency, endocrine, metabolic or central nervous system disorders, pregnant and lactating females, sensitivity to local anaesthetic drugs, allergy to study drugs, $\alpha 2$ agonist or antagonist therapy taken earlier, history of use of any opioid or sedative medications in the week prior to surgery and refuse to give consent were excluded from the study. All the patients were examined a day before surgery and were thoroughly investigated according to the institutional protocol. They were counselled about sedation, comfort, local anaesthesia as well as the operative procedure. The visual analogue scale (VAS) was explained to the patient during the preoperative period.

Patients were randomized according to computer generated random number table into two equal groups, Group D (Dexmedetomidine) and Group PP (PentazocinePromethazine) of thirty patients each. The anaesthesiologist conducting the case, the patients and the the anaesthesiologist in the post anaesthesia care unit (PACU) were all blinded to group assignment. Data was recorded by a blinded observer and the drugs were prepared by an anaesthesiologist who did not participate in patient management or data collection. The study drug solutions were in similar volume of $10 \mathrm{ml}$ loading dose and then maintenance in $50 \mathrm{cc}$ syringe using infusion pump.

On arrival in the operation threatre after confirming adequate nil per oral status, patients heart rate, blood pressure, oxygen saturation, respiratory rate were recorded. Intravenous access was secured with $20 \mathrm{G}$ cannula and Ringer's lactate solution $2 \mathrm{ml} / \mathrm{kg}$ was started. Oxygen was administered via nasal cannula at $2 \mathrm{~L} / \mathrm{min}$. All patients were received Inj. Glycopyrrolate $0.2 \mathrm{mg}$ i.v and Inj. Ondasetron $4 \mathrm{mg}$ i.v. as premedication. Group D received Inj. Dexmedetomidine loading dose of $1 \mu \mathrm{g} / \mathrm{kg}$ over $10 \mathrm{~min}$ followed by a continuous infusion of $0.2 \mu \mathrm{g} / \mathrm{kg} / \mathrm{hr}$ using an infusion pump. Group PP received Inj. Pentazocine $0.5 \mathrm{mg} / \mathrm{kg}$ and Inj. Promethazine $0.5 \mathrm{mg} / \mathrm{kg}$ i.v over $10 \mathrm{~min}$ followed by contionuous infusion of normal saline at $0.2 \mu \mathrm{g} / \mathrm{kg} / \mathrm{hr}$. During this period the patients were assessed every two minutes using Ramsay Sedation Score(RSS). The target end point was a patient having RSS $>3$.If the target end point was reached before completing the loading infusion, then the infusion was stopped and noted. After the loading drug infusion if any patient in either of the groups had lesser sedation (RSS $<3$ ) then bolus IV midazolam $0.01 \mathrm{mg} / \mathrm{kg}$ was administered which was repeated if necessary till RSS was 3.The maintenance infusion in both groups was commenced immediately, once the loading infusions were stopped. After completing the loading infusion of the drugs and when RSS of 3 was achieved, the blinded ENT surgeon administered LA using $2 \%$ lignocaine with adrenaline $(6-7 \mathrm{ml})(1: 2,00,000)$ in the postauricular area, in the incisura terminalis and the four quadrants of the external auditory canal. Surgery was commenced after confirming adequate analgesia. After this patient's vitals - heart rate, respiratory rate, mean arterial pressure, oxygen saturation and Ramsay Sedation Score,
VAS scores were recorded at 1,5,10,15,30,45,60,75,90,120, 150 minutes. If $\mathrm{RSS}<3$, IV midazolam $0.01 \mathrm{mg} / \mathrm{kg}$ was administered as a common rescue sedative in both thr groups. Total number of rescue doses of midazolam was recorded. Intraoperative pain intensity was evaluated using VAS. Inadequate analgesia was treated with infiltration of $2 \%$ lignocaine with adrenaline $(2-3 \mathrm{ml})$ at the surgical site and noted. If the pain was still persistent and VAS $>3$, then rescue IV fentanyl in the dose of $1 \mu \mathrm{g} / \mathrm{kg}$ was given. Total number of rescue doses of fentanyl during surgery was recorded. The protocol specified up to a maximum of three rescue doses each of midazolam and fentanyl. At any time, if clinically indicated or if protocal-specified amounts of rescue drugs were reached, the sedation technique was converted to any sedative or anaesthetic technique and the study drug was discontinued. The maintenance infusions were discontinued at the time of closure which was approximately $15 \mathrm{~min}$ before end of surgery.

Adverse events like bradycardia (Heart rate $<45$ bpm), hypotension (drop in systolic blood pressure $>20 \%$ of baseline or MAP $<60 \mathrm{~mm}$ of $\mathrm{Hg}$ ), hypertension (an increase in systolic blood pressure or MAP $>20 \%$ of baseline), respiratory depression (decrease in respiratory rate $<10$ / min or $\mathrm{SpO} 2$ to less than $90 \%$ was defined as hypoxia ) nausea, vomiting, dry mouth or any other event during or within two hours of the procedure was noted. Bradycardia was treated with intravenous atropine $0.01 \mathrm{mg} / \mathrm{kg}$, hypotension with fluid replacement and if needed, intravenous ephedrine hydrochloride $5 \mathrm{mg}$ in incremental doses was administered. In case of respiratory depression patient was woken up and was asked to take deep breaths. Desaturation was treated by increasing $\mathrm{O} 2$ flow up to 6 liters and if needed, using bag and mask ventilation with 10 liters.

\section{Various Scores Used in the Study}

Ramsay Sedation Score
\begin{tabular}{|l|l|}
\hline 1 & Anxious,agitated or restless \\
\hline 2 & Cooperative,oriented and tranquil \\
\hline 3 & Asleep,responds to command \\
\hline 4 & $\begin{array}{l}\text { Asleep but has a brisk response to light glabellar tap or loud } \\
\text { auditory stimulus }\end{array}$ \\
\hline 5 & $\begin{array}{l}\text { Asleep has a sluggish response to a light glabellar tap or loud } \\
\text { auditory stimulus. }\end{array}$ \\
\hline 6 & Asleep without response \\
\hline
\end{tabular}

\section{Boezaart's Intraoperative Bleeding Scale}

\begin{tabular}{|l|l|}
\hline 0 & No bleeding \\
\hline 1 & Slight bleeding;no suctioning of blood required. \\
\hline 2 & $\begin{array}{l}\text { Slight bleeding;occasional suctioning required.Surgical field not } \\
\text { threatened. }\end{array}$ \\
\hline 3 & $\begin{array}{l}\text { Slight bleeding;frequent suctioning required.Bleeding threatened } \\
\text { surgical field a few seconds after suction was removed. }\end{array}$ \\
\hline 4 & $\begin{array}{l}\text { Moderate bleeding ;frequent suctioning required.Bleeding } \\
\text { threatened surgical field directly after suction was removed. }\end{array}$ \\
\hline
\end{tabular}

At the end of procedure, the field was assessed in respect of bleeding by the surgeon using the scale developed by Boezaart. Patients and surgeons were asked to rate their approval with quality of sedation and analgesia on a seven point Likert Scale. Then patients were shifted to PACU and were monitored for hemodynamic parameters, VAS scores and adverse events, if any for 2 hours till transfer to surgical ward. Requirement of postoperative analgesia was noted. 
The first rescue dose of analgesic was given at VAS $>3$ and was documented.

\section{Likert Scale}

\begin{tabular}{|l|l|}
\hline 1 & Extremely dissatisfied \\
\hline 2 & Dissatisfied \\
\hline 3 & Somewhat dissatisfied \\
\hline 4 & Undecided \\
\hline 5 & Somewhat satisfied \\
\hline 6 & Satisfied \\
\hline 7 & Extremely satisfied \\
\hline
\end{tabular}

Visual Analogue Score $(0-10 \mathrm{~cm})$

\begin{tabular}{|l|l|}
\hline 0 & No Pain \\
\hline 2 & \\
\hline 4 & \\
\hline 6 & \\
\hline 8 & \\
\hline 10 & Worst Pain \\
\hline
\end{tabular}

\section{Statistical Analysis}

Before the study was carried out,a power analysis indicated that 23 patients per group would be required to detect a $10 \%$ difference in haemodynamics parameters. The $\alpha$ error was set at 0.05 and $\beta$ error at 0.9 . Thus sample size of $n=30$ per group was considered for our study. All qualitative data were analyzed using Chi Square test and quantitative data using Student's t-test. All statistical analysis was made using SPSS version 10.0 for windows (Statistical Package for Social Science). All data was presented as Mean \pm SD (Standard Deviation). $\mathrm{P}>0.05$ was regarded as non significant, $\mathrm{P}<0.05$ was regarded as statistically significant and $\mathrm{P}<0.01$ was taken as highly significant.

\section{Results}

There was no statistically significant difference between the two groups with respect to age, sex distribution, ASA physical status, weight and duration of surgery time. $(p>0.05)$ [Table 1].

Mean pulse rate and Mean arterial pressure and were significantly lower in Group D as compared to Group PP during loading dose as well as maintainance and the difference was statistically highly significant. $(\mathrm{p}<.0001)$ [Figure 1,2] Mean respiratory rate and mean oxygen saturation were comparable in both the groups.

Intraoperative mean Ramsay Sedation Score in Group D was $3.33 \pm 0.55$ while in Group PP was $2.60 \pm 0.50$ over initial 10 min which showed more sedation in Group D than Group PP. The difference was statistically highly significant. $(p<0.001)$ [Figure 3] Intraoperative bleeding score and VAS score were significantly lower in Group D than Group PP. $(\mathrm{p}<0.001)$ While Patient's satisfaction score and surgeon's satisfaction score were significantly higher in Group D than Group PP. $(\mathrm{P}<0.001)$ [Table 2] During surgery, only one patient in Group $D$ required recue sedation with midazolam when RSS $<3$ in contrast to four patients in Group $\mathrm{PP}$, though the difference was not $\operatorname{significant}(\mathrm{p}=0.17)$. No patient in either group had $\mathrm{RSS}>3$ at any point during surgery. Eight patients in Group D required rescue local infiltration in contrast to 12 in Group $\operatorname{PP}(p<0.01)$. In Group $\mathrm{PP}$, significantly more number of patients required rescue fentanyl with 10 patients requiring one dose and three patient requiring two doses. In contrast only three patients in Group $\mathrm{D}$ required rescue analgesic( two patients requiring one dose and one patient requiring two doses of fentanyl) $(\mathrm{p}<0.01)$. [Table3] Immediately upon arrival into the recovery room, all the patients in both the groups were able to obey commands. At the end of 30 min patients in both the groups had reached RSS of 2.Time until need for postoperative rescue analgesic was comparable in both the groups $(\mathrm{p}>0.05)$.[Table 3]

\begin{tabular}{|c|c|c|c|}
\hline Parameter & $\begin{array}{l}\text { Group D } \\
(n=30) \\
\text { Mean+SD }\end{array}$ & $\begin{array}{l}\text { Group PP } \\
(n=30) \\
\text { Mean+SD }\end{array}$ & pvalue \\
\hline Age (years) & $27.60+9.70$ & $30.72+11.89$ & \multirow{5}{*}{$>0.05$} \\
\hline $\begin{array}{l}\text { Sex } \\
\text { Male } \\
\text { Female }\end{array}$ & $\begin{array}{l}10(30 \%) \\
20(70 \%)\end{array}$ & $\begin{array}{l}9(26.7 \%) \\
21(73.3 \%)\end{array}$ & \\
\hline $\begin{array}{l}\text { ASA } \\
\text { I } \\
\text { II } \\
\end{array}$ & $\begin{array}{l}26(86.67 \%) \\
4(13.33 \%)\end{array}$ & $\begin{array}{l}27(90.0 \%) \\
3(10.0 \%)\end{array}$ & \\
\hline Weight (kgs) & $61.23+5.01$ & $62.53+5.69$ & \\
\hline $\begin{array}{l}\text { Duration of } \\
\text { Surgery(in min) }\end{array}$ & $121.03+24.69$ & $123.91+22.96$ & \\
\hline
\end{tabular}

Table 2: Boezaart Intraoperative bleeding Score, Patient and Surgeon Satisfaction Score and VAS Score

\begin{tabular}{|l|l|l|l|}
\hline Scores & $\begin{array}{l}\text { Group D } \\
\mathbf{N}=30\end{array}$ & $\begin{array}{l}\text { Group PP } \\
\mathbf{N = 3 0}\end{array}$ & p value \\
\hline $\begin{array}{l}\text { Boezaart Intraoperative } \\
\text { bleeding Score }\end{array}$ & $1-2(1)$ & $2-3(2.4)$ & $<0.001$ \\
\hline Patient's Satisfaction Score & $6-7(5.5)$ & $4-5(4.6)$ & $<0.001$ \\
\hline Surgeon Satisfaction Score & $6-7(5.5)$ & $3-4(3.6)$ & $<0.001$ \\
\hline VAS Score & $3-5(3.5)$ & $6-7(6.8)$ & $<0.001$ \\
\hline
\end{tabular}

Table 3: Rescue sedatives and analgesics and Time to postoperative rescue analgesics

\begin{tabular}{|l|l|l|l|}
\hline & Group D (n=30) & Group PP(N=30) & $\begin{array}{l}\text { P } \\
\text { value }\end{array}$ \\
\hline $\begin{array}{l}\text { Rescue Midazolam } \\
\text { Yes/No }\end{array}$ & & & \\
$\begin{array}{l}\text { No. Of top-ups } \\
(1 / 2 / 3)\end{array}$ & $\begin{array}{l}1 / 29 \\
1 / 0 / 0\end{array}$ & $\begin{array}{l}4 / 26 \\
4 / 0 / 0\end{array}$ & 0.17 \\
\hline $\begin{array}{l}\text { Rescue } \\
\text { infiltration }\end{array}$ & $8 / 22$ & $12 / 18$ & $<0.01$ \\
\hline $\begin{array}{l}\text { Rescue Fentanyl } \\
\begin{array}{l}\text { Yes/No } \\
\text { No. Of top-ups } \\
(1 / 2 / 3)\end{array}\end{array}$ & $3 / 27$ & $13 / 18$ & $<0.01$ \\
\hline $\begin{array}{l}\text { Time until need for } \\
\text { postoperative } \\
\text { rescue } \\
\text { analgesic(min) }\end{array}$ & $157.33(86.74)$ & $10 / 3 / 0$ & $>0.05$ \\
\hline \multicolumn{2}{|l|}{ Data expressed as number (proportion) } & $145.0(109.79)$ & \\
\hline
\end{tabular}

Data expressed as number (proportion)

Table 4: Intra-operative Side Effects
\begin{tabular}{|l|l|l|l|}
\hline Complications & $\begin{array}{l}\text { Group D } \\
\text { N(\%) }\end{array}$ & $\begin{array}{l}\text { Group PP } \\
\text { N(\%) }\end{array}$ & \multirow{2}{*}{ pvalue } \\
\hline Nausea & $2(6.7)$ & $3(10)$ & \\
\hline Vomiting & $0(0)$ & $0(0)$ & \\
\hline Bradycardia & $1(3.3)$ & $0(0)$ & \multirow{2}{*}{$>0.05$} \\
\hline Hypotention & $0(0)$ & $0(0)$ & \\
\hline Oxygen Desaturation & $0(0)$ & $0(0)$ & \\
\hline Hypersensitivity & $0(0)$ & $0(0)$ & \\
\hline Shivering & $0(0)$ & $2(6.7)$ & \\
\hline
\end{tabular}


In Group, 1(3.3\%) patient developed bradycardia which was treated with inj. Atropine $0.6 \mathrm{mg}$ intravenously,2 (6.7\%) patients developed nausea. Where as in Group PP, 3(10\%) patients developed nausea and $2(6.7 \%)$ patients developed shivering. However no major adverse events were observed in both the groups. ( $>>0.05)$ [Table 4] No patients had to be converted to an alternative sedative or anaesthetic therapy in either of the groups.

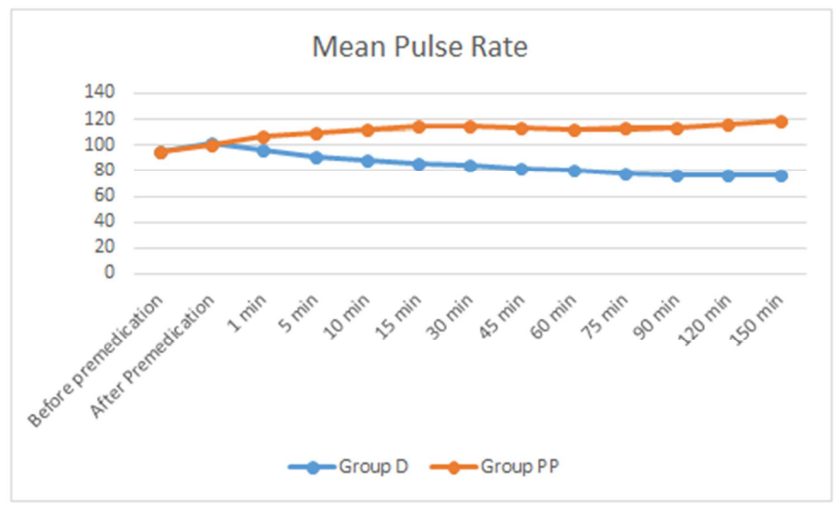

Figure 1: Mean Pulse Rate in Both Groups

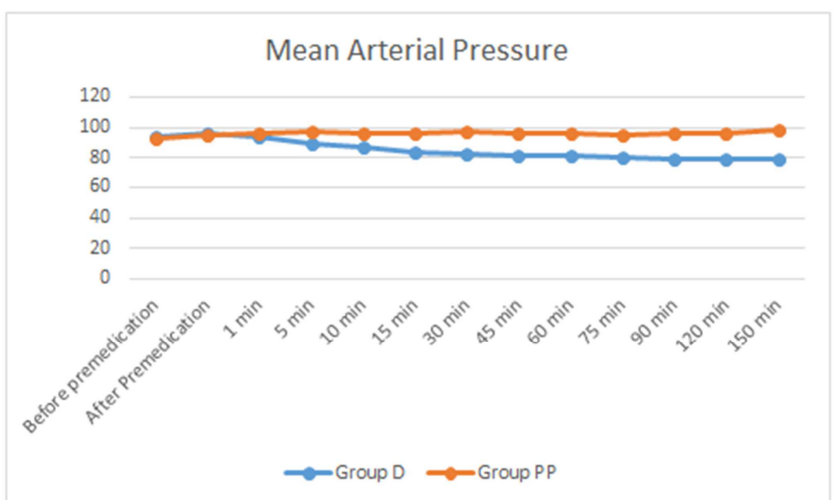

Figure 2: Mean Arterial Pressure in Both Groups

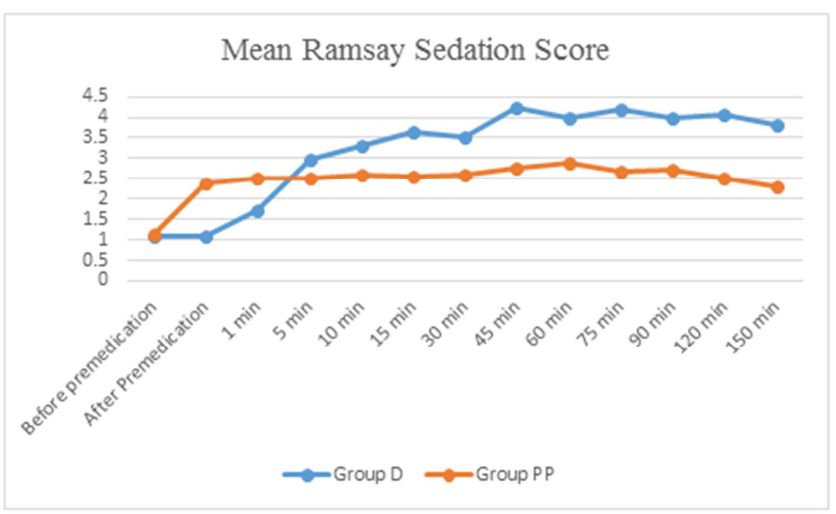

Figure 3: Mean Ramsay Sedation Score in Both Groups

\section{Discussion}

These are various advantages of during operation under local anaesthesia with MAC6-9 especially in day care surgeries. Middle ear surgeries pose a difficult set of challenges for the patient, surgeons and anaesthesiologists. Sympathetic stimulation and movements of an anxious patient cause increased bleeding and disturb the fine microscopic nature of the surgery which may even lead to graft failure. In other hand, a tranquil, peaceful patient with a bloodless field hastens the procedure with great surgeons' satisfaction. Dexmedetomidine, a selective $\alpha_{2}$ adrenoceptor agonist, was approved by the Food and Drug Administrationin 1999 for use in humans as a short term medication ( $<24$ hours) for analgesia and sedation in the intensive care unit (ICU). The presynaptic acivation of the $\alpha_{2}$ adrenoceptor inhibits the release of Norepinephrine, terminating the propagation of pain signals. Postsynaptic activation of $\alpha_{2}$ adrenoceptors in the cental nervous system inhibits sympathetic activity and thus can decrease blood pressure and heart rate. Combined, these effects can produce analgesia, sedation and anxiolysis. Pentazocine is a synthetically prepared prototypical mixed agonist-antagonistopioid analgesic of two enantiomers. High dose may cause high blood pressure or high heart rate. Promethazine is a neuroleptic medication and first generation antihistamine of phenothiazine family. The drug has strong sedative, weak antipsychotic effects, antiemetic and anticholinergic properties. We chose a loading dose of 1 $\mu \mathrm{g} / \mathrm{kg}$ of Dexmedetomidine based on previous literature and studies. ${ }^{[8-15]}$ In view of its short distribution half life of 5-6 minutes dexmedetomidine necessitates that it be given as a maintainance infusion. We selected a maintenance dose of 0.2 $\mu \mathrm{g} / \mathrm{kg} / \mathrm{hr}$, because the surgery was essentially done under local anesthesia. Increasing the infusion rate of dexmedetomidine to maintain desired levels of sedation would also confor additional analgesia and probably resuce the number of rescue fentanyl top-ups in Group D. To avoid this we used a fixed maintenance dose. Additional sedatives and analgesics if required were provided using midazolam and fentanyl so that the rescue drugs were common in both the groups. Also, drugs in both the study groups were targeted to a predefined end point (RSS of 3).

In our study, we have observed that Dexmedetomidine showed better haemodynamic stability in form of controlled hypotention with excellent surgical field, no respiratory depression and no tachycardia even after local infiltration as it is $\alpha_{2}$ receptor agonist. While Promethazine causes deeper level of sedation and some respiratory depression and Pentazocine administration associated with exaggerated increase in heart rate after local infiltration with adrenaline. We compared Dexmedetomidine with PentazocinePromethazine because this combination has been used commonly over years for patients undergoing surgery under MAC.

In our study, Intraoperative Ramsay Sedation Score, Patient comfort and surgeon satisfaction scores were higher in Group D than Group PP which is due to sympathetic blockade and effects on locus coerulus. Through presynaptic activation of the $\alpha_{2}$ adrenoceptors, it inhibits the release of norepinephrine and subsequently decreases sympathetic tone. The results were in accordance with results observed by Parikh DA et al, ${ }^{[10]}$ Verma R et al. ${ }^{[12]}$ Intraoperative Bleeding Scale and VAS Scores were lower in Group D than Group $\mathrm{PP}$. The reason is that dexmedetomidine attenuates the neuroendocrine and haemodynamic responses to anaesthesia and surgery, leading to good sedation and analgesia. ${ }^{[10-13]}$ Lesser number of patients demanded rescue analgesics in Dexmedetomidine group as compared to the pentazocine- 
promethazine group. Analgesic property of $\alpha_{2}$ agonists like dexmedetomidine with its opiate sparing properties has been documented. ${ }^{[14-16]}$ These findings lead to the conclusion that the major sedative and antinociceptive effects of dexmedetomidine are attributable to its stimulation of the $\alpha_{2}$ adrenoceptors in the locus coerulus. ${ }^{[19]}$

Intraoperative side effects in both the groups were not so significant. In Group D, 2 patients had nausea and only one patient developed bradycardia which was treated with injection Atropine $0.6 \mathrm{mg}$ intravenously. An increase in vagal activity may be involved in the haemodynamic effects of dexmedetomidine. ${ }^{[1-14]}$ In Group PP, 3 patients had nausea and 2 patients had shivering.

\section{Conclusion}

We concluded that Dexmedetomidine provides adequate sedation, good analgesia and haemodynamic stability with better surgical field, surgeon satisfaction and patient comfort without any significant side effects for patients undergoing tympanoplasty under Monitored Anaesthesia Care compared to Pentazocine-Promethazine combination.

\section{References}

1. Jackson CG. Principles of Temporal bone and Skull Base Surgery In: Glasscock, editor. Surgery of the Ear.5th edition. New Delhi: Elsevier India;2003. pp.264-6.

2. Liang S, Irwin MG. Review of anaesthesia for middle ear surgery. Anaesthesiol Clin. 2010;28:519-28.

3. Gan TJ. Pharmacologic and pharmacodynamic characteristics of medications used for moderate sedation. Clin Pharmacokinet 2006:45:855-69.

4. Sweetman, S, edition (13 december 2013), "pentazocine.Matindale: The complete Drug reference London,UK: pharmaceutical press, Retrived 17 March 2014.

5. Starke P, Weaver J, Chowdhary B (2005). "Boxed warning added to promethazine labelling in paediatric use. N Eng J Med.352(5):2653

6. Candiotti KA, Bergese SD, Bokesch PM, Feldman MA, Wisemandle W, Bekker AY. Monitored anaesthesia care with dexmedetomidine: A prospective, randomized ,double-blind ,multicenter trial. AnaesthAnalg.2010;110:47-56.

7. Hall JE, Uhrich TD, Barney JA, Arain SR, Ebert TJ.Sedative, amnestic and analgesic properties of small dose dexmedetomididne infusions. Anaesth Analg 2000;90:699-705.

8. Abdulla MI, Mansouri FA,Bener A. Dexmedetomidine during local anaesthesia .J Anaesth 2006;20:54-6.

9. J.A. Alhashemi. Dexmedetomidine vs midazolam for monitored anaesthesia care during cataract surgery. Br. J. Anaesth 2006;96(6):722726.

10. Parikh DA, Kolli SN, Karnik HS, Lele SS, Tendolkar BA. A prospective ,randomized double-blind study comparing dexmedetomidine vs. Combination of midazolam-fentanyl for tympanoplasty surgery under monitored anaesthesia care. J Anaesthesiol Clin Pharmacol 2013;29:173-8.

11. Gupta P, Joshi S, Jethva D, Kumar A. Dexmedetomidine ameliorates monitored anaesthesia care. Indian J Anaesth 2014:58:154-9.

12. Verma R, Gupta R, Bhatia V K, Bogra J, Agarwal S P: Dexmedetomidine and propofol for monitored anaesthesia care during ear surgery. Indian J Otol 2014;20:70-4.

13. Demiraran Y, Korkut E, Tamer A, Yorulmaz I, Kocaman B, Sezen G et al. The comparison of Dexmedetomidine and Midazolam used for sedation of patients during upper endoscopy: A prospective, randomized study. Can J Gastroenterol.2007;21:25-9.

14. Goksu S, Arik H, Demiryurek S, Mumbuc S, Oner U, Demiryurek AT. Effects of Dexmedetomidine infusion in patients undergoing functional endoscopic sinus surgery under local anaesthesia. Eur J Anaesthesiol.2008;25:22-8

15. Mahmoud Hassan Mohamed, Karim Youssef Kamal Hakim. A comparative study between dexmedetomidine/nalbuphine and midazolam/nalbuphine in monitored anaesthesia care during ear surgery. Egyptian J Anaesth, Jan 2014;30(1):7-12.

16. Cheung CW, Ying CL, Chiu WK, Wong GT, Ng KF, Irwin MG. A comparison of Dexmedetomidine and Midazolam for sedation in third molar surgery. Anaesthesia 2007;62:1132-8.

17. Hyo-Seok Na, In-Ae Song, Hong-Sik Park, Jung-Won Hwang, Sang-Hwan Do, Chong -Soo kim. Dexmedetomidine is effective for monitored anaesthesia care in outpatients undergoing cataract surgery. Korean J Anaethesiol Dec 2011;61(6):453-459.

18. American Society of Anaesthesiologists. Distinguishing Monitored Anaesthesia Care ("MAC") from moderate sedation/analgesia. Amended October 212009 and reaffirmed October 2013. Available onlineat :http://www.asahq.org/For-Members/Standar dsGuidelines-and Statements.aspx.

19. Ralph Gertler, H.Cleighton Brown, Donald H.Mitchell, Erin N. SilviusProc(BaylUniv Med Cent):Dexmedetomidine as anovel anaesthetic drug . Jan 2001;14(1):13-21.

Copyright: () the author(s), publisher. Academia Anesthesiologica International is an Official Publication of "Society for Health Care \& Research Development". It is an open-access article distributed under the terms of the Creative Commons Attribution Non-Commercial License, which permits unrestricted non-commercial use, distribution, and reproduction in any medium, provided the original work is properly cited.

How to cite this article: Bhatt KA, Prajapati IA. Comparison of Dexmedetomidine with Pentazocine and Promethazine in Tympanoplasty Surgeries under Monitored Anaesthesia Care: A Prospective, Randomized, Double Blind Study. Acad. Anesthesiol. Int. 2019;4(1):71-75.

DOI: dx.doi.org/10.21276/aan.2019.4.1.16

Source of Support: Nil, Conflict of Interest: None declared. 